\title{
Plasma Theory of Solar Radar Echoes after Thirty Years
}

\author{
Valentin Mel'nik \\ Institute of Radio Astronomy of National Academy of Sciences, 4 \\ Chervonopraporna str., 310002, Kharkiv, Ukraine
}

In 1967 Gordon made the revolutionary assumption that reflection of radar signal from the Sun can be explained by its scattering on microturbulence (Gordon 1973). In his first model it was ion-sound turbulence. Later he considered radar scattering on Langmuir turbulence. The principal opportunity to explain frequency displacements of radar echoes observed in James' experiments (James 1966, 1970) was shown. However, it turned out (Gerasimova 1979) that the mechanism needed an impermissible high level of isotropic turbulence for the reflection with cross-sections $\sigma=10 \pi R_{\odot}^{2}$.

In 1998 (Mel'nik 1998, 1999) a plasma theory of the solar radar echoes in which the reflected signal was formed due to scattering on the anisotropic Langmuir turbulence generated by Type III electrons was proposed. It was shown that in the scope of this theory the main results of James' experiments, like the high $\left(100 \pi R_{\odot}^{2}\right)$, moderate $\left((1-2) \pi R_{\odot}^{2}\right)$, and low $\left(<\pi R_{\odot}^{2}\right)$ effective crosssections, the width $((20-60) \mathrm{kHz})$ of the echo spectrum, the heights $\left(1.3-1.6 R_{\odot}\right)$ at which the main reflections occurred, could be understood. In the region, where $T_{e}>T_{i}$, Langmuir turbulence is a source of ion-sound turbulence and radar scattering on this turbulence can produce reflections high (up to $5 R_{\odot}$ ) in the solar corona. The theory predicts radar reflections with high cross-sections with big frequency shifts. In particular, at definite conditions radar echoes with twice the radar frequency can be possible. The opportunities of coronal plasma diagnostic from the results of the radar experiments are discussed. 1964).

This work was partially supported by INTAS (grant No.96-0183, No 97-

\section{References}

Gerasimova, N.N. 1979, Soviet Astron Zhurn., 56, 1303

Gordon, I.M. 1973, Space Sci. Rev., N447, 1

James, J.C. 1966, ApJ, 146, 356

James, J.C. 1970, MIT Center of Space Res. Techn. Report 70-2, 83

Mel'nik, V.N. 1998, Radiofizika i Radioastronomiia, 3, 12; ibid., 3, 22

Mel'nik, V.N. 1999, Solar Phys., 184, 363; Astronomy Letters, 25, 336 